\title{
Post-operative sleep disturbances
}

\author{
Syed-Nadeem Zaidi FCPS, FCARCSI, Consultant Anaesthetist, Furness General Hospital
}

\section{INTRODUCTION}

Sleep is a normal physiological state in which the human body is less responsive to various external sensory stimuli. Other features of sleep are its reversible nature and a distinct cyclic pattern.

In 24 hours the adult human body needs a minimum of 6-8 hours of sleep. Sleep both in qualitative and quantitative terms is important for physiological replenishment of body reserves and scavenging of various waste products which have been accumulated during the awake state. Various anabolic hormones, e.g. growth hormone, are secreted primarily during sleep. Sleep also has a positive effect on mood, cognitive performance and memory consolidation.

Normal sleep pattern is disturbed after anaesthesia and surgery. Multiple factors have been implicated in this regard. Postoperatively the human body takes some time to restore its regular circadian rhythm of sleep. These sleep disturbances produce a wide range of physical and physiological harmful effects which may increase procedure related morbidity and mortality.

In this review we will discuss some very basic physiologic concepts about normal sleep. Causes of postoperative sleep disturbances, its clinical significance and some remedies to restore sleep in the post-operative period will also be discussed.

\section{NORMAL SLEEP ARCHITECTURE}

Normal sleep is divided into two distinct patterns. These are NREM (non-rapid eye movement) and REM (rapid eye movement) sleep. Table 1 highlights the various differences between NREM and REM sleep. ${ }^{1}$

This NREM/REM sleep occurs in a 90-120 minute cycle with 3-4 cycles per night. The duration of REM sleep increases over the course of the night. Waking up in the morning occurs either in the middle or at the end of REM sleep. Laboratory polysomnography (PSG) is considered as a gold standard to study normal sleep patterns. Normal sleep timing is controlled primarily by two processes. The circadian rhythm or process $\mathrm{C}$ (which is an internal biological clock) activated by various external stimuli and work through a complex neurochemical signals. Process S or homeostasis mechanism is related to active inhibition of reticular activating system (RAS). Balance between waking and sleeping is an important determinant in this mechanism..$^{1-3}$ The duration of normal sleep is affected by many external factors (lifestyle, health, working schedule and stress). Sleep duration and architecture do change with age. Infants and new-borns sleep for 14-16 hours in the day; about $50 \%$ of it is REM pattern sleep. Elderly population often have a fragmented night time sleep. This is exacerbated by a disturbed circadian rhythm and co-existing medical conditions. They spend most of their night time in intermediate phase or N2 stage of NREM sleep. This leads to day time sleepiness, insomnia and fatigue. ${ }^{1}$

Sleep disorders are broadly divided into four categories. ${ }^{2}$ These include insomnia (difficult to go sleep), hypersomnia (difficult to stay awake), parasomnia (abnormal behaviour or movements during sleep) and circadian rhythm disturbances (awake or sleep at the wrong time of day).

\section{SLEEP IN THE POST-OPERATIVE PERIOD}

The triad of general anaesthesia includes a pharmacologically induced state of unconsciousness, akinesia and analgesia. Other features of it are its reversibility and a relative stability of body homeostasis.

Pharmacokinetic profile of most of the general anaesthetics includes lipid solubility, rapid onset and a predictable duration of action. These features allow the human body to regain its homeostatic control quickly after general anaesthetics. Some aspects of body physiology especially circadian rhythm of normal sleep, temperature control and various hormonal secretions (cortisol. melatonin) remain disturbed in the post-operative period for a variable period of time. ${ }^{4,5}$ In the post-operative period, sleep is fragmented with frequent awaking episodes. Total sleep time is also reduced. There is absence of REM sleep with increase in NREM or light sleep. ${ }^{6}$ Many factors have been involved for this disturbed sleep pattern in the postoperative period. Some of them are mentioned in Table 2.

Opioid based anaesthetic techniques have been implicated for a more pronounced effect on post-operative sleep. Opioids, especially morphine, inhibit the REM and stage N-3 of NREM sleep and increase the wakefulness. Morphine has a direct effect on the mu opioid receptor and an indirect inhibitory effect on the release of acetylcholine. Both these actions account for its negative effect on sleep pattern. This effect is dose dependent and reversed with naloxone. ${ }^{7,8}$ Different opioids have a variable effect in this regard. ${ }^{9}$

Post-operative sleep disturbances even occur in young children and infants also, these manifest as negative behavioural changes, anxiety and eating disorders. ${ }^{10}$

\section{CLINICAL SIGNIFICANCE}

Impaired sleep in the post-operative period has physical (fatigue), physiological (impaired immune function) and neurological implications (post-operative cognitive dysfunction). Lack of sleep in the post-operative period has also been linked with wound healing, changes in pain perception threshold and procedure related morbidity and mortality. ${ }^{11}$

Rapid eye movement (REM) sleep is affected most profoundly in the first and second post-operative nights. This is followed by a rebound phase of REM sleep. Effects of REM sleep (increased autonomic system activity, respiratory disturbances, episodes of arterial oxygen desaturation and hypoxemia) are more pronounced during this rebound phase. These changes may have a detrimental effect in the high risk group of patients. The incidence of post-operative cardiac complications, stroke, mental confusion and delirium are much higher on the 3 th and 4th postoperative day which coincides with the rebound phase of REM sleep. ${ }^{11-13}$ 


\section{IMPROVING POST-OPERATIVE SLEEP}

Structural changes in the hospital environment are the key to alleviate sleep related problems. There should be a separate post-operative ward with a quiet environment. Distraction from clinical care should be minimal especially at night times. Appropriate technology should be used to record vital signs. Control of ambient temperature, light and noise levels in the ward are very important to promote sleep. Use of eye masks and ear plugs is a helpful strategy against these external factors. ${ }^{14-16}$ Some hospitals have adopted a quiet time programme with good results regarding promotion of sleep in hospitalised patients. ${ }^{17}$

Anaesthetically regional and multimodal analgesic techniques should be practised for post-operative pain control. Laparoscopic surgical techniques reduce the severity of surgical stress thus promoting the early resumption of normal sleep pattern.

Uses of both pharmacological (short acting benzodiazepines, anxiolytics, dexmedetomidine) and non-pharmacological techniques (relaxation, music, aromatherapy, day time light exposure) have been reported in literature with positive results. ${ }^{16}$ The aim of all these techniques is to re-establish the normal physiological circadian sleep rhythm in the post-operative phase.

\section{CONCLUSION}

Normal sleep architecture is disturbed in the postoperative recovery phase. Evidence suggests that it have a multifactorial aetiology. Factors intrinsic to patients are sometimes difficult to change. Hospital related environmental factors (noise, light, temperature) and patient care related factors need modification and change.

Anaesthetically multimodal analgesic techniques should be practised to promote early resumption of routine activities. Laparoscopic assisted surgical techniques are helpful in minimising the stress response related to surgery thus improving the quality of sleep in the post-operative period.

Many aspects of the subject remain unexplained. It requires more experimental work and multicentre trials to find some workable and practical solutions to this problem.

\begin{tabular}{|c|c|}
\hline NREM Sleep & REM Sleep \\
\hline First stage of sleep & It follows NREM sleep \\
\hline $\begin{array}{l}\text { Has three different sub stages } \\
\text { - N1 - transitional phase between awake and sleep } \\
\text { - N2 - is an intermediate phase } \\
\text { - N3 - deep sleep also called (slow wave sleep) }\end{array}$ & $\begin{array}{l}\text { Has two different sub stages } \\
\text { - tonic stage (Para sympathomimetic) } \\
\text { - phasic stage (Sympathomimetic) }\end{array}$ \\
\hline Consists of $75-80 \%$ of total sleep time & Consists of $20-25 \%$ of total sleep time \\
\hline Duration gradually $\downarrow$ over the course of night & Duration gradually $\uparrow$ over the course of night \\
\hline $\begin{array}{l}\text { Physiological changes } \\
\text { - } \text { heart rate } \downarrow \\
\text { - } \text { blood pressure } \downarrow \\
\text { - } \text { sympathetic nervous system activity } \downarrow \\
\text { - } \text { air way resistance } \uparrow \\
\text { - muscle tone same as awake state } \\
\text { - } \text { brain activity } \downarrow \\
\text { - } \text { blood flow to brain } \downarrow\end{array}$ & $\begin{array}{l}\text { Physiological changes } \\
\text { - heart rate } \uparrow \text { or irregular } \\
\text { - blood pressure } \uparrow \text { or variable } \\
\text { - } \text { sympathetic nervous system activity } \uparrow \\
\text { - respiratory rate } \uparrow \text { or variable } \\
\text { - } \text { air way resistance } \uparrow \text { or variable } \\
\text { - muscle tone } \downarrow \text { or absent } \\
\text { - brain activity } \uparrow \\
\text { - blood flow to brain } \uparrow\end{array}$ \\
\hline $\begin{array}{l}\text { Dreams } \\
\qquad \text { not present }\end{array}$ & $\begin{array}{l}\text { Dreams } \\
\quad \cdot \text { active dreaming (dreams remembered) }\end{array}$ \\
\hline $\begin{array}{l}\text { Other features } \\
\text { - easy arousability with external sensory stimuli } \\
\text { - both eye and active body movements are absent } \\
\text { during sleep }\end{array}$ & $\begin{array}{l}\text { Other features } \\
\text { - active body movements } \\
\text { - more difficult to wake up with sensory stimuli } \\
\text { - rapid eye movements }\end{array}$ \\
\hline $\begin{array}{ll}\text { EEG } & \\
\text { - N-1 } & \text { theta waves } \\
\text { - N-2 } & \text { sleep spindles } \\
\text { - N-3 } & \text { delta waves }\end{array}$ & $\begin{array}{l}\text { EEG } \\
\text { - Pattern resembles awake (low voltage, } \\
\text { high frequency waves) }\end{array}$ \\
\hline
\end{tabular}

Table 1: Differences between the two sleep patterns 


\section{1) Surgical stress \\ - depends upon type and duration of surgery \\ - healing process}

\section{2) Post-operative pain}

\section{3) Hospital atmosphere}

- ambient light

- noise

- monitoring equipment

- doctor and nursing activities (ward round, vital sign monitoring, medicine administration)

- disturbance from fellow patients

\section{4) Effect of anaesthetics}

- opioid base techniques especially morphine

\section{5) Change of personal routine}

6) Psychological factors

- related to underlying pathology

\section{7) Pre-existing sleep disorders}

- obstructive sleep apnoea

- narcolepsy

- insomnia

- restless leg syndrome

Table 2: Post-operative sleep disturbances - commonly involved factors

\section{REFERENCES}

1. Carley DW, Farabi SS. Physiology of sleep. Diabetes Spectrum 2016;29(1):5-9.

2. Hall A. Sleep physiology and the perioperative care of patients with sleep disorders. BJA Education 2015;15(4):167-172.

3. American Academy of Sleep Medicine: The international classification of sleep disorders; 3 rd ed. Darien, IL: American Academy of Sleep Medicine, 2005.

4. Gogenur I, Wildschiotz G, Rosenberg J. Circadian distribution of sleep phases after major abdominal surgery. British Journal of Anaesthesia 2008;100(1): 45-49.

5. Cronin AJ, Keifer JK, Davis MF, King TS, Bixler EO. Melatonin secretion after surgery. Lancet 2000;356:1244-1245

6. Dette F, Cassel W, Urban F, et al. Occurrence of rapid eye movement sleep deprivation after surgery under regional anaesthesia. Anesth \& Analg 2013;116(4):939-943.

7. Cronin AJ, Keifer JC, Davies MF, King TS, Bixler EO. Post-operative sleep disturbance: influence of opioids and pain in humans. Sleep 2001;24(1):39-44.

8. Shaw IR, Lavigne G, Mayer P, Choiniere M. Acute intravenous administration of morphine perturbs sleep architecture in healthy pain free young adults: a preliminary study. Sleep 2005;28:677-682.
9. Wenk M, Popping DM, Chapman G, Grenda H, Ledwski T. Long term quality of sleep after remifentanil -based anaesthesia: a randomized controlled trial. British Journal of Anaesthesia. 2013;110(2):250-257

10. Steinmetz, J, Holm-Knudsen R, Eriksen K, Marxen D, Rasmussen LS. Quality differences in postoperative sleep between propofol -remifentanil and sevoflurane anaesthesia in infants. Anesth Analg. 2007;104(4):779-783.

11. Chouchou F, Khoury S, Chaunty J-M, Denis R, Lavigne GJ Post-operative sleep disruptions: A potential catalyst of acute pain? Sleep Med Rev 2014;18(3):273-282

12. Kaw R, Michota F, Jaffer A, Ghamande S, Auckley D, Golish J Unrecognized sleep apnoea in the surgical patient: implications for the perioperative setting. Chest 2006;129(1):198-205

13. Hillman DR. Post-operative sleep disturbances: understanding and emerging therapies. Advances in Anaesthesia. 2017;35:1-24.

14. Su X, Wang D. Improve postoperative sleep: what can we do? Curr Opin Anesthesiol. 2018;31:83-88.

15. Dubose JR, Hadi K. Improving inpatients environments to support patient sleep. International Journal for Quality in Health Care. 2006;28(5):540553

16. Dolan R, Huh J, Tiwari N, Sproat T, Brenan JC. A prospective analysis of sleep deprivation and disturbance in surgical patients. Annals of Medicine and Surgery. 2016;6:1-5.

17. Maidl CA, Leske JS, Garcia AE. The influence of "Quiet Time "for patients in critical care. Clin Nurs Res 2014;23:544-559.

Correspondence to: syed-nadeem.zaidi@mbht.nhs.uk 